\title{
PARTIAL THYROIDECTOMY FOR CATATONIC DEMENTIA PRÆCOX.
}

\section{A Final Report Concerning Investigations into this}

SUBJECT.

By ALLEN B. KANAVEL, M. D.,

Assistant Professor of Surgery, Northwestern University Medical School,

AND

LEWIS J. POLLOCK, M.D.,

Senior Physician, Cook County Institutions, Dunning, Illinois.

Chicago, Illinors.

At the last meeting of the Illinois State Medical Society, held at Quincy, ${ }^{1}$ we presented a preliminary report upon this procedure, introduced by Berkley and reported ${ }^{2}$ in the AMERICAN JouRNAL OF INSANITY in January I909. In that report we stated that the procedure had been absolutely without avail in old cases and that as yet sufficient time had not elapsed to make a final report concerning those cases operated upon within a short time after the onset of the disease.

Although somewhat skeptical at that time as to the favorable outcome even in recent cases, we felt that the greatest conservatism should be exercised since if this procedure offered the slightest grounds for hope in this otherwise hopeless group of cases the research should be prosecuted to the final conclusion.

We, therefore, prefaced our report with the following statement:

Before beginning a discussion of this subject we wish to emphasize that the present contribution is but a preliminary report upon which we feel an ultimate decision cannot be based. It is but a report of work in progress. We wish to be neither ultra-conservative nor over-enthusiastic, but desire to maintain a strictly scientific attitude of investigation and wish not to be betrayed into either advising or condemning the procedure.

${ }^{2}$ A Preliminary Report upon the Advisability of Thyroidectomy in Catatonic Dementia Præcox. By Allen B. Kanavel, M. D., in association with Lewis J. Pollock, M. D. and Arthur B. Eustace, M. D. Illinois Medical Journal, September, 1909.

An Investigation into the Merits of Thyroidectomy and Thyrolecithin in the Treatment of Catatonia. By Henry J. Berkley and Richard $\mathrm{H}$. Follis, the A Merican Journal of InSANITY, January, 1909. 
A basis for some encouragement was found in the fact that Berkley had subjected eight cases to operative interference and five of these had shown an apparently perfect recovery. Moreover, there seemed to be some theoretical and experimental support to the proposition. The disease often arises at puberty when the ovaries and the thyroid, in common with other organs, take on a change of function. The inter-relation of these glands and the fluctuation of the thyroid at various phases of ovarian activity is well known. Again, Hunt in developing the acetonitril test, found that the ovaries, testicles, mammary glands, and prostate contained a substance acting feebly like thyroid. Berkley had seemed to demonstrate that dessicated thyroid gland and iodine aggravated the symptoms of catatonic dementia præcox, and finally there was the chance similarity between the symptoms and signs of this disease and thyro-toxicosis; for instance the increased reflexes, hyperidrosis, tremor, skin changes and loss of weight.

Moreover, in view of the reversions which Wilson and Marine and Williams have shown to occur in exophthalmic goitre, it may be said that the pathological condition of the glands while not distinctly favoring the assumption of an etiological relationship is not incompatible with it as will be seen by examining the pathological reports herein attached.

At the time of making our preliminary report there had been a complete lack of result in the patients who had suffered from the disease over one year; of two cases under that time one had just been operated upon and hence could not be used in making our deductions while the other case operated upon four months previous had apparently recovered and his parole was contemplated. Since the preliminary report was made, however, the patient who had apparently recovered has gradually relapsed into his previous state and the other case operated upon, remains absolutely unimproved to all intents and purposes.

The case mentioned in the preliminary report as having apparently recovered after having had a considerable tumor of the thyroid removed has now returned with a complete relapse after an absence of eight months in which he remained practically well.

A summary of our personal cases which includes one not here recorded, therefore allows only a report adverse to the procedure. The list of cases which should have recovered was very small, therefore, one of us (A. B. K.) wrote to Professor Berkley stating 
our unfavorable results in late cases and the lack of distinct pathological support as shown by our old cases; and we here append a part of his letter which bears directly upon the subject :

Your letter of the 16 th inst. reached me this morning. You are only obtaining the results two other surgeons have done (in three cases operated on by them), and for reasons unknown to me, possibly because the cases were not pure catatonia or possibly because they did not do the same operation Dr. Follis has done. All I can now add to the article in the January number of the JouRnal of INSANITY is that we partly thyroidectomized three additional cases and that they all recovered perfectly, and have remained in perfet mental health since their recovery from the operation.

Dr. Follis and I have proceeded with the utmost caution in selecting our cases and have oft times rejected as many as twenty successive cases before coming to one that we concluded was suitable for operation from the mental and blood examination standpoints.

Now that we know more about these cases than we did two years ago, we are turning down more and more cases in proportion to the number accepted and have no idea of its becoming a panacea for catatonia. All we now look for is to obtain good results in a very limited number of well-selected examples of this malady.

The suggestions of Berkley here, and in his article, in reference to the non-improvement of certain cases, that the duration may have been too long, the cases not properly selected, and that a sufficient amount of thyroid gland may not have been removed suggest certain pertinent remarks. It seems to us that the choice of cases based upon the duration of the illness is not an entirely scientific one, inasmuch as the rapidity of the course cannot be ascertained and the determination of where brain changes supersede the perverted thyroid gland function, cannot be made. Again, from the standpoint of the symptomatology it is entirely possible to meet with a psychosis presenting in its early stages the catatonia which later may be found not to belong to the adolescent group. We have demonstrated conclusively that the pathological appearance of the gland is of no importance from a diagnostic or prognostic standpoint. The mere examination of the blood by ordinary methods does not help in choosing the cases. In other words, if the procedure is of any value there is no satisfactory method of selecting favorable cases. Finally, there must also be considered the occurrence of remissions which are present from a few hours to a few days in almost all cases; and in almost 20 per cent of the cases, the occurrence of a relapse within the 
first five years, long enough for the patients to have seemed to have recovered. Therefore, the greatest care must be exercised not to report cases as cured too early as might easily have been done in our cases that improved temporarily.

A summary of the facts as they now stand concerning the question of thyroidectomy in this condition may be stated as follows:

Our two cases of pure catatonic dementia præcox of short duration which should have had favorable results, showed no result in one case and a temporary improvement in the other. The third case with the enlarged gland (operated upon by Dr. Rowan) which seemed to recover, has now relapsed. Our older cases showed no results, and the pathological examination of the gland in these cases, as well as in the younger ones, showed nothing positively in favor of the assumption of an etiological relationship, although the changes might be compatible with it.

On the other hand, Berkley has now had eight cases he has apparently cured, and while evidently most conservative, is still inclined to favor the operation in well-selected cases.

Our personal conclusion must be that it is certainly not justified in any large class of cases, and although it may be a possibility in a few cases in the early catatonic stage, possibly where the thyroid gland shows change, even here nothing definite can be promised and ultimately it may be necessary to withdraw even this slight hope of aid in this group of psychoses.

We herewith append a report of the pathological findings and the essential details of the histories of the cases operated upon.

The operation was extremely simple in every case. The skin and platysma only were cut, the deeper muscles retracted to one side. Seven eighths $(7 / 8)$ of one lobe was removed and the wound closed with silk worm gut drainage. The operation took only a few minutes and the patients were up the following day if they desired. The cases were operated upon with the assistance of $\mathrm{Dr}$. A. B. Eustace and the pathological examinations were made by Professor F. R. Zeit, of the Northwestern University Medical School.

CASE I.-A catatonic incidentally operated upon for relief of dyspncea, etc., caused by a thyroid tumor.

E. D., male, age 22, woodworker. Family and personal history negative. Of previous illnesses, had measles when two; present illness dates back to 1906, commencing with mannerisms, etc., suggestive of dementia præcox. He showed during the course hallucinations of sight, some fantastic de- 
lusions and excitement followed later by an indolent, stupid, emotionally indifferent, catatonic state. Physically, he showed a large thyroid tumor, more marked upon the right side, dyspnca and metallic voice. Operated upon August 12, 1908, by Dr. Rowan; on the 24th, the stitches were removed and the patient had improved physically; September, 1908, he showed marked improvement mentally, the hallucinations disappeared and thought process became clear; September 16, 1908, he was paroled to his mother; three days later went to work; he was returned to the institution August 5, 1909, in a mute catatonic condition.

Case II.-A. E., male, age 28, clerk. Family and personal history negative. Present illness dates back to 1906, when he became listless and delusional, but continued to work until 1908; admitted to the institution April, 1908, when he was stupid, indolent, had some hallucinations of hearing and showed lack of voluntary activity. He continued in this state and upon examination, December, 1908, showed physically all somatic signs of catatonia, cyanosis of extremities, increased reflexes and dilated pupils; psychically was a dull, indolent catatonic with marked negativism. Operated upon February I, uneventful recovery from operation; has remained in the same condition since the operation.

Pathology of Gland.-Gross weight $15 \mathrm{gm}$., moderately vascular, small hard mass the size of a pea palpable in gland. Microscopical diagnosis: Struma parenchymatosa. The alveoli are markedly enlarged, the colloid markedly increased. Alveoli are lined with several layers of epithelial cells and islands of parenchyma cells are irregularly arranged between the alveoli. The vessels are slightly distended with blood and hemorrhages have occurred into the stroma extensively. In a few places blood is noted filling the alveoli. The stroma is slightly œdematous. In some places the contents of the alveoli are of a serous nature not staining deeply, but for the most part they take the stains well. Some few show no contents.

CASE III.-W. T., age 28, R. R. employe, male. Family history negative. Personal history; has always been rather unruly and drunk alcohol excessively. Previous illnesses; diphtheria and syphilis. Present illness dates back to June, 1907, when he became careless as to appearance, in January, 1908, he became delusional, and showed marked fabrication. Admitted to the institution January, 1908, when he presented the appearance of a paranoid dementia pracox with physical findings of cyanosis of the extremities, dermographism and hyperidrosis; he ran a course presenting foolish, unsystematized delusions, foolish behavior, grimacing and at times mutism to a degree. January, 1909, was in good physical condition, blood pressure, sys. 130, dias. 100, red cells $4,500,000$, whites 8000 . Blood clots in four minutes. Operated upon February 1, 1909; uneventful recovery from the operation. Escaped from the institution February 19, was returned in the same conditon as existed before the operation, and has since then remained the same.

Pathology.-Weight $25 \mathrm{gm}$., moderately vascular, normal in size and color, small fat-like body removed, found to be parathyroid. Microscopical diagnosis: Struma colloides. The majority of the alveoli are markedly distended with colloid. The interstitial tissue is slightly œdematous; 
here and there small islands of parenchyma cells are found in the interstitial tissue; blood vessels are normal and no hemorrhages present, contents stain well in practically every part. In one alveolus is noted a marked cauliflower growth.

CASE IV.-E. K., male, age 28, draughtsman. Family and personal history negative. Of previous illnesses had diphtheria as a child. Present illness commenced to years ago, when he became excited, following an altercation with his father. After this developed hallucinations of sight and delusions of persecution, became retarded in action and was emotionally indifferent. Five years ago he became catatonic, showing cerea flexibilitas and mutism; with the exception of one remission lasting two months, he has remained in this condition (January, 1909). Examination revealed: Physically cyanosis of the extremities, cold, clammy skin, increased reflexes, etc. Blood pressure, sys. 125, dias. 90; blood clots in four minutes, red 6,000,000; whites 10,000. Psychically an extreme example of catatonia. Operated upon February 8, 1909, has remained in the same condition since the operation.

Pathology.-Thyroid paler, but not larger than normal; weight $\mathbf{1 7 . 3 3}$ gm.; microscopical diagnosis: Moderate struma colloides. The alveoli are markedly distended and lined with a flattened epithelium. There is some interstitial parenchyma hyperplasia. A few of the acini are lined with several layers of cells; there is is no œdema of the interstitial tissue although slight hemorrhage is noted throughout.

CASE V.-F. W., male, age 20, laborer. Family and personal history negative. No previous illnesses. Present illness: When 16 , was always depressed and of a retiring disposition, two years ago became careless in appearance, apathetic and indolent. Admitted to the institution April 12, 1908. Physically in good condition, psychically indolent, and careless; mute to a degree; January, 1909, showed physically cyanosis, hyperidrosis, dilated pupils and increased reflexes; blood pressure, sys. I50; dias. 100; red 6,000,000; whites 8000 . Psychically remains as before. Operated upon February I, 1909; remains the same as before operation, although for a short time he took a more active interest in his surroundings.

Pathology.-Weight $39 \mathrm{gm}$. Microscopical diagnosis: The structure is found to be normal except for a few hemorrhages between the alveoli and distention of a few alveoli, showing flattened epithelium and an increased amount of colloid; the lining epithelium contains but one layer of cells.

CASE VI.-R. F., male, age 23, teamster. Father died insane at the age of 35. Personal history negative. Of previous illnesses had scarlet fever as a child. Present illness began April 19, 1908, with worry, then the development of mutism, had vague delusions of persecution, admitted to the institution May, 1908, in a catatonic condition, staring stolidly before him, answering all questions with "I don't know-I couldn't say." An examination in January, 1909, showed physically, somatic signs of catatonia, blood pressure, sys. I25; dias. 90 ; red 6,000,000; whites II,500 Psychically showed some delusions of persecution, great emotional deterioration, attention very difficult to obtain and interest very slight; re- 
mains mute at times except when hard pressed. Operated upon February 8, 1909. February I5, showed slight improvement, wants to work. February 22, is up working about the ward, taking interest in his surroundings. March I, patient markedly improved, wants to be interviewed to prove that he is well, wrote a letter to the physician telling of his improvement, an act of volition certainly not present before the operation. May 8, has begun to re-develop delusions of persecution with onset of carelessness in his appearance, reluctance in answering questions; there is no hypertrophy of the thyroid gland. After having been paroled and returned in a few weeks in the same condition as existed previous to the operation he has so remained.

Pathology.-Same as in case V.

CAsE VII.-J. U., age 19, male, laborer. Family and personal history negative. Present illness dates back to February, 1909, when he became reclusive, constantly examined his face, developed hallucinations of hearing; admitted to the institution, October, 1907, in a catatonic condition. Examination, January, 1909, shows physically the signs of catatonia; psychically mutism, some negativism, emotional deterioration and filthiness. Blood pressure, sys. 120; dias. 80. Operated upon February 8, 1909, he has remained in the same condition as existed before the operation.

Pathology.-Weight $18.75 \mathrm{gm}$. Normal gland markedly hyperæmic, interstitial stroma is not œdematous but there are many hemorrhages, slight increase of connective tissue between the alveoli.

Case VIII.-J. L., male, 25. Family and personal history negative. Previous illnesses: Typhoid fever when 2 years old, measles at 6, developed pulmonary tuberculosis at 18 . At that time present illness began; he became delusional, acted in a peculiar manner and was admitted into the institution July, 1905; when he presented the picture of a negativistic mute catatonic. Examination, February, 1908, showed physically, besides the signs of catatonia, blood pressure, sys. I30; dias. 90; red 6,000,000; whites 8000 . Psychically a mute catatonic. Operated upon February 15, 1909, has remained in the condition present previous to the operation.

Pathology.-Moderate struma colloides. Microscopical examination: Large alveoli in patches with moderate degree of hyperæmia with extensive hemorrhages in the interstitial tissue. The epithelial lining is thinned.

Case IX.-H. H., male, age 19, schoolboy. Family and personal history negative. Present illness dates back to 5 years ago, when he refused to eat and became very irritable, admitted to the institution November, 1907, paroled January, 1908. Readmitted July, 1908, examination January, 1909, showed psychically a very foolish hebephrenic, having numerous mannerisms and grimaces; physically negative; blood pressure, sys. 120; dias. 80 ; red 5,500,000; whites 8000 ; blood clots in four minutes. Operated upon February 15; remains in no way improved.

Pathology.-Moderate struma colloides. Microscopical examination: Alveoli are distended in islands and lined with low flattened epithelial cells. Here and there are islands of epithelial cells in the interstitial stroma and lining some of the alveoli are several layers of cells; hyperzemia is marked. Moderate degree of interstitial hemorrhage. 
Case X.-R. E., male, age 28, machinist. Family and personal history negative. Admitted to the institution September, 1906, when he showed verbigeration, decreased volitional impulses, was indolent, later developed marked negativism, became mute and refused food. Examination January, 1908, showed marked cyanosis, etc., blood pressure, sys. 130, dias. 105; red 6,000,000; whites 8500 ; blood clots in five minutes. Psychically, an extremely negativistic, mute catatonic with great emotional deterioration. Operated upon February 15, has remained in the same condition as existed previous to the operation.

Pathology.-Moderate struma parenchymatosa, with atrophic thyroid. Microscopical examination: Alveoli are not increased in size; the interstitital connective tissue is slightly increased, the organ is markedly hyperæmic and a moderate degree of hemorrhage present. The epithelial tissue is markedly increased in the alveoli in places.

CASE XI.-F. T., female, age 25, clothing cutter. Family history negative. Personal history: She was always neurotic, and would be annoyed at trifles; at 17 commenced to worry over religion; continued in this way until 1907 , when she developed attacks in which she would throw herself around for a long period of time; in November she became delusional and was admitted to the institution December, 1907. Physically showed cyanosis of extremities, otherwise negative. Psychically, hallucinations of hearing, poor attention, emotionally depressed and fearful, conduct very foolish, continuing she became mute, listless and careless in appearance. Examination January, 1909, she showed physically marked dermographism and cold, clammy skin; psychically in the same condition as above described. Blood pressure, sys. 140, dias. 100; blood clots in four minutes, red 5,000,000; whites 9000. Operated upon February 15, 1909, has remained in the same condition since operation.

Pathology.-Struma colloides, et hemorrhagica. Microscopical examination: Many of the alveoli are distended with colloid; the epithelium is thinned out and the cells flattened, in other places it is normal; there is marked hyperæmia and extensive hemorrhages into the interstitial tissue and alveoli; no œdema is found in the interstitial tissue; there are a few islands of parenchyma cells, a small parathyroid was noted.

CASE XII.-C. H., age 23. Personal and family history negative; previous illness: Syphilis when 19. Admitted to the institution February, 1909. Physically in good condition; psychically very confused; showed marked emotional deterioration, took a long time to answer questions. He ran a course developing mutism, some negativism and became extremely careless as to appearance. The course was intercepted by numerous remissions lasting from a few minutes to several hours. Examination May I, 1909, mentally in the state described above, physically showed cold, clammy skin, increased reflexes, blood pressure, sys. 130, dias. 80 ; blood clots in four minutes, reds 6,000,000; whites 10,000. Operated upon May 15. For the week following the operation he showed numerous remissions lasting several hours, since then he has reverted into his former condition of mutism and so continues. 